\title{
CONTRIBUCIÓN AL ESTUDIO DE LAS UNIDADES DE EXPLOTACIÓN EN CASTILLA LA VIEJA
}

\author{
Jesús García Fernández
}

*El texto de este artículo constituyó el tema de la conferencia pronunciada por el autor, el día 5 de marzo de 1984 , en las Segundas Jornadas de Geografía, organizada por el Instituto Universitario de Geografía de Alicante.

Es indudable que el importante éxodo rural que ha padecido la región ha dado lugar a una acusada concentración de las unidades de explotación agraria. Ha sido la contrapartida, y diríamos que positiva, al vaciamiento que ha experimentado. Hecho que, sin embargo, no es debidamente conocido; y que enmascaran las estadísticas oficiales, dando una idea completamente errónea de la realidad. Sigue estando vigente el tópico del minifundismo castellano.

Ya en otra ocasión señalé que raro era el agricultor, propiamente dicho, que trabajase menos de 50 ha en secano, y que la mayoría de ellos labraban más de 100 ha. Así mismo indiqué que son estos últimos una minoría, los que cultivan con sus unidades de explotación la mayor parte de la superficie de cada término municipal e incluso en bastantes casos prácticamente la totalidad de su terrazgo ${ }^{1}$. Hecho que se aviene mal con las ideas al uso sobre la región; pero que había sido inducido del conocimiento de las transformaciones que ha experimentado la explotación agraria en la mayor parte de las campiñas del Sur y centro de la Cuenca sedimentaria; en las comarcas de páramos, e incluso en sectores de las Montañas, que tienen mayor aptitud agrícola, como la de las Loras y el Páramo de la Lora. Y tal cambio, a lo largo de la década del sesenta, ha ido acompañado de una mejora sensible en las técnicas de explotación, en la productividad, en la producción y en el nivel de vida de los agricultores que han logrado formarse tales unidades de explotación. Su incidencia desde el punto de vista económico ha sido grande: ha sacado al campesinado de la miseria de antaño. Hoy son muchos menos; pero con una capacidad económica mucho mayor. [222]

Estudios posteriores, unas veces puntuales; y otras, en muestras a mayor escala, realizados en el Departamento de Geografía de Valladolid, han empezado a captar esta otra realidad del hogaño de nuestra región. No es ahora el momento de antuviar tales investigaciones todavía en curso. Pero sí voy a hacer uso de un ensayo de verdadero censo de explotaciones, que por los años 1972-74 realizó el IRYDA en cuarenta y un municipios de la Tierra de Campos de la provincia de Valladolid, y cuya Delegación ha proporcionado generosamente una copia a nuestro Departamento. Esta fuente adolece aún de cierta imprecisión, explicable por ser un primer, y loado intento en este arriscado terreno. En ella figuran más unidades de explotación de las que en realidad hay. Pero aun así no deja de ser muy valiosa.

$\mathrm{Su}$ análisis detenido es lo que me ha permitido orientar las nuevas pesquisas con otra orientación, al confrontar los datos de esta fuente con la realidad y otros documentos. Pero, además, los resultados que de ella se obtienen no dejan de ser expresivos, y una confirmación de las ideas esbozadas a suso.

\section{La importancia de las unidades de explotación de más de 100 ha}

Para estos 41 municipios hay un total de 1.489 unidades de explotación, computando

\footnotetext{
${ }^{1}$ J. García Fernández: Desarrollo y atonía en Castilla. Barcelona. Ariel. 1981. 262 págs.
} 
entre ellas las que sus titulares dan a labrar a otros, y que nosotros denominamos dependientes. Pues bien, las de más de 100 ha son 302 (20,2 por 100); pero, cultivan bastante más de la mitad del terrazgo, un 60,5 por 100 (véase Cuadro I). Su importancia es manifiesta; más, si tenemos en cuenta que de las que no llegan a este umbral, muchas, o son ficticias, o no se comportan en realidad como verdaderas explotaciones rurales.

Y la importancia de las unidades de explotación de este tipo todavía aparece más acrecentada, si del conjunto se excluye las dependientes, pues, como tales sólo existen a efectos estadísticos; ya que aparte de ser en general de muy pequeñas extensiones -nos lo demuestra la superficie que ocupan que ni siquiera llega a la décima parte del terrazgo- ni por su trabajo, gestión e innovaciones técnicas, y rentabilidad, entran dentro de lo que se debe entender por una explotación agraria propiamente dicha. Descontadas, las de más de 100 ha suponen algo más de un tercio $(37,4$ por 100$)$ del total de explotaciones y cultivan casi las dos terceras partes del terrazgo -66,2 por 100- (Véase Cuadro II). Las unidades de explotación de menor tamaño cuentan así realmente poco, especialmente las de menos de 50 ha, que abarcan poco más de un 10 por 100 de la superficie cultivada. Y tampoco el que sean numéricamente mayoría unas y otras debe inducirnos a pensar en un grave desequilibrio. Ya precisaremos que la mayor parte no existen nada más que a efectos contables; en realidad son muchos menos.

El valor que en la explotación agraria tienen estas unidades de explotación de más de 100 ha parece evidente; es preponderante desde el punto de vista económico [223]

CUADRO I

Clasificación de las unidades de explotación totales

\begin{tabular}{|l|c|c|l|c|}
\hline Tipo de explotaciones & Núm. & $\%$ & Superficie & $\%$ \\
\hline
\end{tabular}

Unidades de explotación

dependiente 602

De menos de 50 ha

40,43

9.219

9,50

De 51 a 100 ha

22,22

10.207

10,51

De 101 a 250 ha

17,06

18.831

19,41

De más de 250 ha

59

16,32

36.606

37,72

De mas de 250 ha....

3,97

22.172

22,86

\begin{tabular}{|l|l|l|l|l|}
\hline TOTAL .......................................... & 1.489 & 100,00 & 97.035 & 100,00 \\
\hline
\end{tabular}

y hasta social; de ellas procede tanto la proporción más importante de la producción, como de las rentas del campo. Y semejante hecho queda corroborado porque esta composición de las unidades de explotación aparece generalizada. De los 41 municipios considerados, en 31 eran netamente predominantes, y hasta tal punto que la superficie que englobaban en su gestión casi llegaba a las tres cuartas partes de su terrazgo. Y de los otros diez términos municipales, en ocho, las unidades de explotación de 50 a 100 y 101 a 250 ha ocupaban una proporción del labradío mayor, casi rayana en las cuatros quintas partes $(79,7$ por 100$)$. Si no había producido la transformación que en la mayoría, había estado a punto de conseguirse. Tan sólo en dos municipios el predominio de las unidades de explotación tradicional era completo. Son la excepción que confirma la regla. 
CUADRO II

Unidades de explotación independientes según su tamaño

\begin{tabular}{|c|c|c|c|c|}
\hline Tipos de explotaciones & Núm. & $\%$ & Superficie & $\%$ \\
\hline 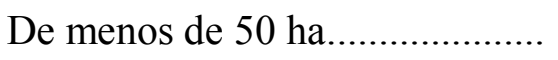 & 331 & 37,31 & 10.207 & 11,63 \\
\hline 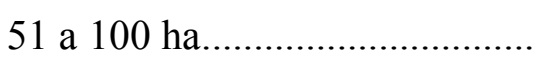 & 254 & 28,64 & 18.831 & 21,44 \\
\hline 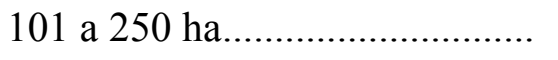 & 243 & 27,39 & 36.606 & 41,68 \\
\hline Más de 250 ha................................. & 59 & 6,66 & 22.172 & 25,25 \\
\hline 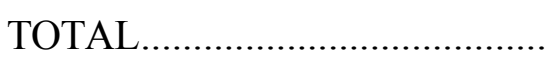 & 887 & 100,00 & 87.816 & 100,00 \\
\hline
\end{tabular}

Y tales datos revelan una concentración muy superior de la que se advierte por la comparación de los Censos agrarios de 1962 y 1972, este último contemporáneo [224] de ellos; y también de la que se deja entrever de un estudio realizado seriamente sobre un sector de la misma comarca ${ }^{2}$. Concentración que se ha podido conseguir por un rápido proceso de motorización, como nos demuestra el hecho de que la potencia media para las explotaciones activas o independientes fuese de $0,65 \mathrm{CV} / \mathrm{ha}$, y para el total de las explotaciones de $0,58 \mathrm{CV} / \mathrm{ha}$; más que suficiente para atender a la superficie que les correspondía, y aun, una bastante mayor.

Y semejante concentración no ha sido resultado de una transformación radical de la estructura de la propiedad, que por el contrario parece haber quedado bastante intangible, sino que se ha producido fundamentalmente por un aumento sensible de las unidades de explotación tradicionales más características, las típicas del par de mulas -alrededor de las 30 ha-; y menos de las grandes, también tradicionales, englobando las tierras de los que han emigrado, principalmente por distintas formas de arrendamiento $\mathrm{y}$, en mucha menor proporción, por adquisición. Así la disociación entre unidades de propiedad y de unidades de explotación es completa.

Hecho que si lo pone de manifiesto esta muestra de 41 municipios de Tierra de Campos tiene un mayor carácter de generalidad en la región. Aunque con algunos matices ha sido constatado, a pesar de no haber sido estudiado tan detenidamente, en la prolongación NO de esta Comarca, en Campos de Villadiego y Melgar de Fermental, en las Campiñas de Medina del Campo, de Olmedo y Moraña, así como en los páramos de Torozos, en los de Cuéllar y Peñafiel y en los de Cerrato, y los burgaleses del Ubierna y Castrojeriz. Y en todas estas comarcas, si bien no siempre se rebasa el umbral de las 100 ha, se está próximo a él. El grado de concentración de las explotaciones es de igual naturaleza. Es decir, y tratándose de unidades de explotación de secano, aunque en algunos casos incluyan una mayor o menor proporción de regadío, prácticamente abarca a todas las Llanuras de la Cuenca sedimentaria. Y en unos y en otros sectores esta importante transformación de tal aspecto de la estructura agraria, que no de la propiedad, se ha realizado por el mismo proceso. De ahí, que lo dominante en el aprovechamiento agrícola de la región se siga realizando fundamentalmente a base de unidades de explotación familiar. El Censo que nos ha servido de base nos lo demuestra; pero, además, nos descubre otros aspectos que han sido constatados en la realidad.

\footnotetext{
${ }^{2}$ M. Peña Sánchez: Crisis rural y transformaciones recientes en Tierras de Campos. Departamento de Geografía de la Universidad de Valladolid. 1975. 347 págs. Cf/págs. 197 y siguientes.
} 


\section{El valor de las unidades de explotación familiares}

El análisis individualizado de cada una de las unidades de explotación de más de 100 ha -272 de las 302 de este tamaño, porque de 30 de ellas se [225] carece de los suficientes datosnos pone de manifiesto que las explotaciones agrupadas o comunitarias tienen una importancia relativamente pequeña: sólo son 58, poco más de una quinta parte del total, y tampoco abarcan una gran superficie, el 27,3 por 100. En cambio, las que aparecen registradas en forma nominal, individuales -de corporaciones o sociedades sólo hay una de 214 ha- ascienden a 213 y cultivan 36.555 ha, es decir, más de las dos terceras partes ( 72,2 por 100) de la superficie que pertenece a esta clase de unidades de explotación.

Y esta diferencia no hoy, sino también a comienzos de la década del setenta, es en realidad mucho mayor. Un buen número si no una mayoría, de las explotaciones comunitarias o agrupadas no eran tales. Salvo una cooperativa, y no grande, todas eran grupos sindicales de colonización, que encubrían diversas ficciones: proindivisos, cuyos propietarios buscaron esta fórmula jurídica; grandes fincas -la mayor explotación de todo el conjunto con 1.155 ha- y agrupaciones de 4 ó 5 personas que, vinculadas por lazos familiares, en realidad labraban independientes los unos de los otros. En estos tres casos, la agrupación no fue sino un sobrehaz para obtener subvenciones oficiales y otras ventajas. No faltaron, y todavía existen, verdaderas explotaciones comunitarias, que tanto en el espíritu como en la letra funcionaron como tales. Pero todo da a entender que son una exigua minoría. De ahí, que sea a través de las unidades individuales por las que se realiza fundamentalmente el aprovechamiento del suelo. Éstas son las que merecen nuestra atención.

Pues bien, de éstas, la mayor parte, casi la mitad, entran dentro de la categoría de explotaciones familiares, entendiendo por tales en las que el trabajo es esencialmente familiar. Una proporción elevada -el 29 por 100- son mixtas, es decir, predomina la mano de obra asalariada, aun cuando interviene el trabajo del titular o de uno de sus familiares; y, por último, una cuarta parte -25,3 por 100- está constituida por explotaciones que sólo utilizan mano de obra asalariada. Ahora bien, esta triple apreciación, que no clasificación, no debe entenderse como que las primeras corresponden a las de menor superficie; las segundas sean de tamaño medio, y las terceras estén representadas por grandes explotaciones de tipo latifundista. Al contrario unas y otras aparecen en los distintos umbrales. (Véase Cuadro III). Hoy con una mecanización apropiada dos o tres personas pueden llevar una extensión grande de terreno; y éstas pueden ser miembros de una familia. La mayor explotación familiar con 254 ha, y una potencia de 0,39 $\mathrm{CV} /$ ha está llevada por dos hermanos. Una explotación con una sola unidad de trabajo abarca 184 ha con un tractor de $61 \mathrm{CV}$ que maneja su titular. En los momentos actuales, cuando se dispone de medios y redaños para el trabajo, las explotaciones familiares pueden tener un tamaño grande, y sobrepasar lo que se entiende por rentable. [226]

Bien es cierto que, por el origen que han tenido estas explotaciones familiares, predominan en los umbrales de 101 a 120 y 121-150. Pero tampoco faltan en ellas, las unidades de explotación que utilizan también mano de obra asalariada o están labradas únicamente por obreros, aunque éstas sean más propias del umbral superior a 250 ha.

Precisamente por esto, aunque mano de obra familiar y asalariada varían respectivamente inversamente proporcional al tamaño de las explotaciones, los obreros están presentes en todos los umbrales (Véase Cuadro IV); y en esta representación llaman la atención dos hechos, que en los momentos actuales son ostensiblemente sorprendentes: $1^{\circ} .^{\circ}$ Que en las explotaciones de 100 a 150 ha hay un número de ellas, que están llevadas única y exclusivamente por obreros, o que tengan un complemento de mano de obra asalariada. No parece justificado, ya que hoy una sola persona puede con un 


\begin{tabular}{|c|c|c|c|c|c|c|c|c|c|c|}
\hline \multirow{3}{*}{$\begin{array}{c}\begin{array}{c}\text { Su } \\
\text { Explotaciones } \\
\text { has. }\end{array} \\
101-120\end{array}$} & \multirow{2}{*}{$\begin{array}{l}\text { uperficie } \\
\text { Núm. }\end{array}$} & \multirow{3}{*}{$\begin{array}{l}\text { Has. } \\
6.135\end{array}$} & \multicolumn{7}{|c|}{ Tipos de explotaciones (Número y \%) } & \multirow[b]{2}{*}{ Total } \\
\hline & & & $\%$ & Fan & niliares & Tra & b. asala. & & ixtas & \\
\hline & 55 & & 16,79 & 37 & 67,28 & 7 & 12,72 & 10 & 20,00 & $55 \quad 100$ \\
\hline $121-150$ & 67 & 9.014 & 24,65 & 37 & 55,24 & $15 !$ & 22,38 & 15 & 22,38 & $67 \quad 100$ \\
\hline $151-200$ & 46 & 8.055 & 22,03 & 17 & 36,95 & 8 & 17,39 & 21 & 45,66 & $46 \quad 100$ \\
\hline $200-250$ & 16 & 3.574 & 9,78 & 4 & 25,00 & 4 & 25,00 & 8 & 50,00 & 16100 \\
\hline Más de 250 & 29 & 9.777 & 26,75 & 1 & 3,44 & 20 & 68,97 & 8 & 27,59 & $29 \quad 100$ \\
\hline Total & 213 & 36.555 & 100,00 & 96 & 45,08 & 54 & 25,35 & 63 & 29,5 & 213100 \\
\hline
\end{tabular}

tractor apropiado trabajar esta superficie o mucho mayor. $2 .^{\circ}$ ) Tampoco parece justificado, a la luz de nuestros días naturalmente, que haya explotaciones grandes en donde la presencia del titular, que también lo es propietario, esté por completo ausente. Y si en unos casos se trata de explotaciones ya verdaderamente grandes -500 a 700 ha- en otras no, ya que sobrepasan en poco las 200 ha. Explotaciones del mismo tamaño que otras, en las que el titular dirige, e incluso trabaja, ayudado por obreros. [227]

\begin{tabular}{cccccccc}
\hline $\begin{array}{c}\text { Explotaciones } \\
\text { Has. }\end{array}$ & Núm. & Familiar & $\%$ & Asalariada & $\%$ & Total & $\%$ \\
\hline $101-120$ & 55 & 71 & 74,73 & 24 & 25,27 & 95 & 100 \\
$121-150$ & 67 & 85 & 64,88 & 46 & 35,12 & 131 & 100 \\
$151-200$ & 46 & 55 & 52,38 & 50 & 47,62 & 105 & 100 \\
$201-250$ & 16 & 17 & 42,50 & 23 & 57,50 & 40 & 100 \\
Más de 250 & 29 & 14 & 12,84 & 95 & 87,16 & 109 & 100 \\
\hline Total & 213 & 242 & 50,41 & 238 & 49,59 & 480 & 100 \\
\hline
\end{tabular}

\section{Los tipos de unidades de explotación: un ensayo de clasificación}

La utilización de mano de obra asalariada en unidades de explotación de 101-150 ha responde a diversas circunstancias. En unos casos se trata de explotaciones labradas por su titular con un hijo, o sólo son éste o aquél; pero que también incluyen en su gestión ganado -generalmente un rebaño de ovejas-, y naturalmente requieren un pastor, que entra dentro de la categoría de mano de obra asalariada. En otros son explotaciones que pertenecen a mujeres, solteras o viudas, que por consideraciones sociales, contratan obreros fijos para la obtención de las cosechas, desempeñando un papel de dirección más o menos efectivo; pero nunca considerándose como agricultores. Por último, en otras, generalmente las explotaciones que rebasan sensiblemente las 200 ha, difícilmente pueden ser gestionadas con una sola persona. El titular, que es a la vez propietario -en estos casos hay coincidencia entre unidad de explotación y de propiedad- dirige, e incluso, y cada vez más, trabaja, con la ayuda de uno, dos o tres obreros, según el tamaño, pero rara vez más, el conjunto que le pertenece. Se trata en este último tipo de las grandes explotaciones de los labradores hacendados, muy característicos de la Comarca, que teniendo como única profesión la agricultura, se han adaptado a los tiempos presentes. 
Pero en estos tres casos aún estamos dentro de la explotación familiar, modernizada en forma independiente de su tamaño, aunque el carácter empresarial en unas sea muy feble y en otras evidente. No ocurre así en otros casos, que pudiéramos denominar de residuos de las explotaciones tradicionales, cuyo único aspecto de modernidad es haber adaptado la maquinaria. En una comarca donde la unidad típica era el par de mulas, toda propiedad que [228] sobrepasaba las 100 ha era considerada, y efectivamente lo era, como una gran explotación. Sus poseedores entraban dentro de la categoría de labradores hacendados, que por sus rentas, que les permitían un sistema de vida de cierto nivel, formaban una clase social que se diferenciaba del resto del campesinado: de los agricultores -pequeños propietarios autónomos-; de los colonos -los que para completar lo que les faltaba para labrar con el par de mulas tenían que recurrir a arrendar tierras, las peores parcelas de los grandes propietarios- y de los gañanes, los obreros que aunque tuviesen algo de propiedad, tenían que recurrir al trabajo asalariado para subsistir. Y uno de los elementos de distinción de esta clase de labradores hacendados era el que sus hijos hiciesen estudios universitarios. Así, con el tiempo han adquirido otras profesiones, y han quedado desarraigados del campo; viven en las ciudades más o menos alejadas de la comarca. Pero han conservado las tierras que les correspondieron por herencia, unas veces en forma de proindiviso; otras en forma individual. Y ya que tienen este medio de producción, no renuncian a obtener de él cualquier clase de beneficio que pueda proporcionarlos.

Pero, absorbidos por otras ocupaciones, frecuentemente más lucrativas, aunque residan en las ciudades más próximas, ni tienen tiempo, ni tienen conocimientos para dirigir la explotación. Tienen que confiarla por completo a una mano de obra asalariada y hasta jerarquizada, en la que la figura del cachicán es la más importante. Si los tiempos les han obligado a la mecanización, la organización de la explotación tiene una estructura tradicional, que en los momentos actuales resulta un tanto arcaica. Ayunos de los conocimientos precisos utilizan una mano de obra enteramente desmesurada. Así, se dan casos de explotaciones de 150 ha que emplean tres obreros, que no están justificados ni siquiera por la existencia de un rebaño de ovejas, por otro lado muy pequeño -215 ó 360 cabezas-. Pero a veces en explotaciones de algo menor cuantía -143 ha- son también tres los asalariados que las trabajan. En las de mayores dimensiones este hecho está todavía más acusado. Una explotación de 290 ha, aunque también con un rebaño mayor -630 ovejas- emplea seis obreros. El exceso de mano de obra es evidente; las primeras, en otros casos de verdaderas explotaciones familiares, están llevadas por uno, y todo lo más, por dos personas, en el caso de que haya ganado; y las segundas por dos o tres, e incluso cuatro, si se da esta última circunstancia.

$\mathrm{Y}$ es indudable que estas explotaciones pertenecientes a propietarios absentistas difícilmente se les puede calificar de agrarias, son meras productoras de rentas para personas ajenas por completo a la vida rural. A las más pequeñas cabe denominar las explotaciones tradicionales residuales; y a las segundas las mayores, las de más de 250 ha, de explotaciones latifundistas en el sentido peyorativo que ha adquirido esta palabra. La diferencia con las otras [229] -las familiares propiamente dichas, y lasfamiliares de carácter empresarial- es manifiesta. Mientras éstas con su trabajo, gestión, gastos e ingresos contribuyen a la prosperidad de la economía rural; las otras son meras predadoras de capital que es sustraído al campo. E1 significado de unas y otras es bien distinto, tanto desde el punto de vista económico como social.

La diversidad que presentan, por lo tanto, las unidades de explotación de más de 100 ha es relativamente grande. Esto nos lleva a señalar lo arriscado que es realizar su clasificación en función exclusiva de su tamaño, ya que puede enmascarar por completo la realidad, cuando no conducir a verdaderos marramientos. Igualmente parece delicado establecer un umbral de viabilidad o rentabilidad, ya que ésta no debe ser la misma para todos los tipos que hemos esbozado, porque sus problemas no son los mismos. Es indudable que las que rebasan las 120 y las 150 ha, si descansan en el trabajo de sus titulares, pueden entrar dentro de esta 
cualificación; pero no siempre en igual medida. Por eso, el estudio de las unidades de explotación debe ser orientado teniendo, además, en cuenta otros criterios que los meramente cuantitativos; y desde luego ser conducido con un grado de acuidad, que refleje de la mejor forma posible lo compleja que es la realidad.

Y otro tanto cabe considerar para las unidades de explotación que son inferiores a las 100 ha. Parecen criterios un tanto estólicos, encuadrar las que se acercan a esta cifra como en el camino de la viabilidad; y estimar que las de menos de 50 ha son las tradicionales, con carácter de subsistencia, incapaces de proporcionar un nivel de vida ni siquiera aceptable; y sobre todo apoyar en ellas la idea de que son el peso muerto del campo castellano, porque son las más numerosas. Aquí caben todos los tópicos de curso forzado. Dejando aparte las de regadío, o las que tienen una elevada proporción de él, que son caso aparte, es más una cuestión a estudiar que a enunciar, aun con cálculos que no pasan de lo teórico. Lo que sí cabe esbozar es que la última idea no es enteramente cabal, porque ni son tantas, ni muchas de ellas son en realidad tales explotaciones agrarias. Bajo los índices numéricos se esconde una gran diversidad de situaciones, reflejo de las transformaciones que ha experimentado la región, y de las coyunturas de la economía general de nuestros días.

Muchas de ellas lo mismo en el Censo, que hemos considerado que en otros documentos de curso legal no existen nada más que a efectos oficiales, en realidad son parte de otras explotaciones. Si se mantienen así es por exigencias de la vida rural. Más que ficciones jurídicas, aunque también lo sean, son un aspecto de la bergancia a que las circunstancias fuerzan al campesino. Así su número es mucho menor del que puede figurar en cualquier estadística; y las tan cacareadas explotaciones marginales de la región no existir en innumerables casos. El problema no aparece así tan desmesurado; aunque sí encierre [230] otros problemas. Porque, de hecho, existen muchas de estas pequeñas explotaciones, aun hecho este importante desglose. Lo que ya es otra cuestión es si pueden ser consideradas en puridad como constituyendo explotaciones agrarias.

Ya hemos calificado algunas como dependientes, las que sus titulares dan a labrar a otros; también son sólo una fuente de rentas, basadas tan sólo en el capital, sin que el trabajo intervenga para nada. Y ya hemos visto que por su número son mayoría (40,4 por 100), aunque abarquen una superficie exigua. De ellas unas favorecen a gentes del campo, campesinos viejos, que incluso cobran la pensión de la seguridad social, y ni tienen capacidad física ni legal para trabajarlas. Pero, otras, a quien benefician es a los habitantes de la ciudad, antiguos emigrantes, hoy trabajadores de la industria y de los servicios, generalmente bien remunerados, que en vez de arrendarlas hacen que otros las labren por ellos con un trabajo alquilado. Invierten en la explotación de la tierra, porque de ella obtienen un beneficio complementario nada despreciable. Esta otra clase de absentistas acuden sólo en el verano al pueblo que les vio nacer a pasar las vacaciones, y a hacer el agosto, expresión que en estos casos cobra todo su significado. Y estas unidades en poco contribuyen a la economía rural, son sólo una fuente de rentas basada en el sacrosanto derecho de la propiedad privada, que por privar de tierra a los que las trabajan, y sin duda, la necesitan, bien merecen el calificativo de los latifundios minifundistas. Y estos dos tipos de explotaciones calificadas de inviables existen, y han resistido a todos los cambios, precisamente porque son viables como complemento de otros ingresos. Lo que ya es una cuestión diferente es si verdaderamente son rentables para la economía rural.

Y el número de estas explotaciones, mayor que las estadísticas dan a entender, reduce mucho el dramatismo que se ha puesto, tanto por desconocimiento como por otra clase de intereses, de estas explotaciones calificadas de marginales. Ocurre otro tanto con otras muchas de estas pequeñas unidades de explotación, a veces de muy reducida extensión -10-15 e incluso 20 ha-, y que han resistido a todos los avatares. Hoy, en la época que el tractor exige unas dimensiones de escala muy superiores, parece increíble que puedan existir. Se resisten a toda 
lógica; pero, por irracionales, no dejan de tener su razón de ser. Entran dentro de ese concepto ambiguo de agricultura de tiempo parcial. Desde luego sus titulares, incluso trabajándolas, no son propiamente agricultores, y a veces, tampoco habitantes del campo. Pues dentro de este concepto se pueden distinguir dos variedades: una, la de explotaciones que forman parte de ámbito rural; y otra, que es la de los cultivadores urbanos.

La primera ha existido siempre, y aunque todo da la impresión de que tiende a desaparecer, todavía pervive. Se trata de propietarios pequeños que [231] tienen otras profesiones (comerciantes, empleados en los servicios, dueños de pequeños negocios locales), y cuyas tierras, precisamente porque no requieren mucho tiempo, ni exigen altos costes de explotación, las labran a ratos perdidos o las dan a labrar a otros en algunas ocasiones. De lo que obtienen de ellas no depende su vida; y produzcan más o menos, es siempre un ingreso adicional. De verdaderas explotaciones agrarias tienen poco; pero, en este caso, son de gentes del espacio rural, y a él van a parar los beneficios de ellas.

No es lo mismo para la otra modalidad que se ha detectado. Ésta aparece constituida por antiguos emigrantes, hoy residentes en las ciudades próximas, en donde son trabajadores de la industria principalmente, menos en los servicios, y bien situados. Su vida la tienen asegurada con este empleo; y las tierras como un complemento. Son los que no han optado ni por venderlas -raro es el emigrante que lo hace- ni por arrendarlas, ni siquiera por darlas a labrar a otros, sino por trabajarlas ellos mismos. Como no ocupan gran extensión, en los fines de semana, ahora que comienzan el viernes por la tarde, les bastan a algunos para sembrarlas, quizá algún otro para el abono de cobertera, si es que no lo encargan, o para ver cómo va la marcha de la cosecha, y el permiso del verano para vigilar la recolección, realizada con cosechadoras alquiladas. El atrojar el grano y el venderlo no requiere mayor esfuerzo. Así unidades de explotación que antes no les permitían vivir, por eso emigraron, hoy tienen otro interés mucho más estimulante. Es cierto que estos domingueros, como los apodan los verdaderos agricultores, obtienen sus beneficios de la tierra mediante su trabajo; pero, muy poco es lo que contribuyen a la economía rural, ni en ingresos que se encauzan a la ciudad, ni en trabajo, para los residentes, porque lo realizan por sí. Son los que causan más irritación entre los campesinos residentes. Así, gracias a estos agricultores urbanos, unidades de explotación que no son rentables adquieren rentabilidad y justifican su pervivencia.

Ahora bien, estas unidades de explotación pequeñas sean dependientes, bien de residentes, bien de absentistas -los latifundistas del minifundio-, o bien sean de agricultura a tiempo parcial, lo mismo de residentes que de urbanos, no se les puede calificar propiamente de agrarias. Sus titulares no son agricultores de profesión, sino que tienen otra profesión. Son marginales; pero no porque no consientan nada más que un nivel de subsistencia, sino porque están al margen de la economía rural. Y si son un peso muerto para ésta, lo es más porque impiden un mayor desarrollo de la riqueza de la región, que no porque distribuyen equitativamente la miseria para la mayor parte de los campesinos. Pues, ya se ha podido apreciar, que ni son tantas en realidad, ni para sus detentadores dejan de ser rentables. El problema no es para ellos; todo lo contrario, sino para los verdaderos agricultores, y para la economía agraria de la región. Y si estas unidades de explotación no son agrarias, ni [232] marginales, ni un peso muerto en el sentido que se les ha dado, sí son esto otro, un problema. Pero un problema entre los otros que presentan las otras unidades de explotación, y estrechamente relacionado con ellas. Es decir, un aspecto del complejo de problemas que todas presentan en conjunto.

\section{Los problemas de las unidades de explotación}

Si complejo es el panorama de tipos de explotaciones agrarias, también son complejos los problemas que plantean. Distintos y con diferente significado para cada una de estas 
variedades que he intentado esbozar. Pero igualmente se imbrican los unos con los otros, a pesar de ser de desigual naturaleza; y crean tensiones entre unos tipos de agricultores, que si hoy aparecen a somormujo, pueden hacerse más patentes -ya se han empezado a hacer-, producir fisuras en una sociedad rural, que conserva una gran homogeneidad en su comportamiento, y comprometer logros indudables de la economía rural de la región, o de una parte de ella.

El problema es más grave allí donde parece que es menos aparente, e incluso que no existe: en las unidades de explotación familiares propiamente dichas. Son las que por absorción de tierras de otros han pasado de la dimensión del par de mulas a la escala del tractor, con más de 100,150 y aun más hectáreas. Son las que verdaderamente han experimentado una transformación sorprendente, y han contribuido en mayor medida que cualquiera otras a la profunda renovación que ha experimentado el campo castellano. Indudablemente han llegado al umbral de rentabilidad, y hoy proporciona un acomodo en el que, ni sus titulares pensaban al iniciar el proceso hace veinte años, ni mucho menos podían suponer sus padres en una vida de brega cotidiana, llena de lacericas y de pobreza. Se puede pensar que han llegado a la estabilidad deseada. Hay bastante de ello; pero también de lo contrario. Más que fortaleza adolecen de debilidad; y más que de seguridad para el futuro tiene mucho de incertidumbre, lo que no quiere decir que carezcan de él.

El acrecentamiento que han experimentado ha sido, como hemos señalado, fundamentalmente por arrendamiento. Éste, en la casi totalidad de ellas, afecta a la mitad de las tierras; en muchas, a una mayor proporción; y en las comarcas que han experimentado un muy acusado vaciamiento son bastantes las que no tienen prácticamente tierras propias. Y aquí empieza su problema. Los arrendamientos sean antiguos o modernos suponen siempre una detracción importante del producto bruto, que cada vez se deja sentir más al aumentar los gastos de explotación; reduce el margen de beneficios. Pero además conlleva la inseguridad. La venta por parte de los propietarios, y a medida que el precio de la tierra aumente, es una amenaza, que está presente, aun en los arrendamientos más favorables, los realizados entre hermanos. Y la adquisición [233] en estas condiciones es una victoria pírrica. El deseo de estas unidades de explotación es hacer de su propiedad, y aun adquirir más, todas las tierras que trabajan, ya que ni potencia, ni mano de obra, ni espíritu de riesgo le faltan, pero no a los precios completamente desorbitados que hoy tiene. Y estos elevados precios son desorbitados por el enrarecimiento del mercado, prácticamente paralizado.

Y semejante paralización es una consecuencia de la escasez de oferta. Nadie quiere vender. Las rentas seguras del arrendamiento retraen a los posibles vendedores. La tierra es cara porque hay arrendamientos; y hay arrendamientos porque la tierra es cara, y se espera que lo sea más. Es un círculo vicioso. Pero no el único. Y aquí el problema de las unidades de explotación familiares se imbrica con el que plantean las llamadas marginales, las pequeñas que subsisten.

Las dependientes que dan la tierra a labrar a estas otras, y las de tiempo parcial que igualmente producen una renta segura, sin gran esfuerzo, ni muchos costes, también contribuyen al enrarecimiento del mercado: es un capital que por plusvalía crece artificialmente en proporción geométrica. Así su supervivencia contribuye a la subida de los precios. En estas condiciones los verdaderos agricultores no pueden comprar; y el que puede, o se ve obligado a adquirir, paga la tierra a precio de oro. El círculo vicioso se hace más complejo: no se compra porque no se vende y no se vende porque no se compra. La codicia soterrada es un sobrehaz que oculta un problema acerbo. Todavía manifiesto con sordina; pero que ya ha hecho su aparición.

Los que disponen de unidades de explotación familiares con esta onerosa composición ya han empezado a descubrir el problema en estos dos frentes. Piensan que un sistema fiscal, que grave más y proporcionalmente a las pequeñas superficies, hoy por la cuota proporcional poco costosa, o nada, para sus propietarios, acompañada con una desgravación por trabajo personal, flexibilizaría el mercado de tierras. A los arrendadores, a los absentistas, una contribución 
apropiada convertiría sus rentas en irrentables, se verían obligados a vender. Critican, también, la legislación vigente en materia hereditaria que hace inevitable la fragmentación de la propiedad, y obliga al hermano que se ha quedado en la explotación paterna a ser rentero de los que han abandonado el campo y tienen otras profesiones. Estima que, aun dentro de un respeto a la propiedad privada, el sistema habría de ser reformado en beneficio del que realiza el trabajo, tanto para que no se merme su capacidad económica, como para que tuviese una completa seguridad ante el futuro, al no estar amenazado de amputación por venta de parte de su unidad de explotación. A su juicio, los que han buscado otras profesiones fuera del ámbito rural ya están suficientemente compensados con un empleo estable y bien remunerado. [234]

Es más, piensan que el agricultor debe ser un profesional de la agricultura, y que la actividad agraria debe ser exclusiva para los que a ella dedican todo su esfuerzo. Por eso, critican a los que practican la agricultura a tiempo parcial, sean residentes o absentistas, y en especial a estos últimos, ya que les privan de unas tierras que ellos necesitan, y que los otros trabajan deficientemente para obtener unos ingresos suplementarios. La mentalidad de incompatibilidades ha prendido también en esta clase de agricultores; y se juzga poco justo que haya gente que tiene otra fuente de ingresos, y siga ostentando sin ningún inconveniente su propiedad, que para ellos tiene más de detentación que de legítima posesión.

Hoy por hoy, sólo se piensa, y se comentan estas cuestiones; y esto es ya un toque de atención. Pero, es indudable que se está configurando una nueva mentalidad, que puede aglutinarse en una ideología campesina, que en el futuro puede crear tensiones más ásperas en una sociedad caracterizada hasta ahora por su estabilidad. Mentalidad que incluso aparece ya enteramente configurada. Más, cuando en los momentos de crisis general, la emigración parece haber dejado de ser la solución. Estas unidades de explotación necesitan crear más empleo, aumentando sus dimensiones de escala, como respuesta a una egresión cada vez más difícil y hasta imposible. Y las nuevas generaciones que desean, y tienen que quedarse en el campo, no piensan que se tenga que dar pasos atrás, y que el agricultor haya de volver a ser un ciudadano de segunda categoría. El problema, que ya es actual, puede agravarse en un futuro inmediato. Hasta ahora se había acallado, que no resuelto, con las subidas de los precios agrícolas. Pero también se piensa que, aun siendo éstos importantes, no toda la solución está en ellos, puesto que no resuelven todos los problemas. Y aquí los problemas de esta clase de agricultores se une, y hasta se contrapone, a los de las otras que hemos señalado.

Para las unidades de explotación familiar de carácter empresarial y para las de tipo latifundista, en las que la propiedad coincide generalmente con la superficie labrada, el gasto más gravoso está constituido por el trabajo asalariado. Es su verdadera gangrena. La mano de obra, tanto porque es escasa, como por consideraciones sociales, se encarece a mayor ritmo que cualquier otro coste. Es lo que más merma su beneficio. Ante este hecho inevitable para estos propietarios todo es un problema de precios. Son los más interesados en la imagen de una región minifundista. Las explotaciones pequeñas, las inviables que ofrecen las estadísticas, les sirve de pantalla para forzar la subida de los precios. Y hasta ahora más influyentes, y con más resortes, lo habían conseguido; pero no en la medida deseada. Con ello han logrado mantener su nivel de rentas, aunque cada vez con un menor margen. En cambio, han beneficiado indirectamente a las unidades de explotación familiares, [235] que se basan en su propio trabajo, y cuyos ingresos se embarnecen en mayor proporción.

Semejante paradoja no deja de sustentar tensiones. Los más grandes propietarios ven, con cierta aspereza, que los pequeños les igualan, que incluso obtienen más beneficios, y que pierden prestigio y fuerza. Éstos encuentran su base más firme en el trabajo, y piensan, como ya hemos visto, que en el campo, que cada vez es más suyo, sus problemas no sólo son de precios, que hay otros más importantes, y que el de los precios, aun siendo para ellos una ventaja, es también un problema, porque lo es, pero a escala general de la economía de la región, y aun a otra de 
mayores dimensiones.

Suben, y subirán más; pero también se considera que alguna vez habrán de llegar a su techo. Y esto ya parece haber llegado. Pero lo que es indudable es que estos precios se transfieren en costes más o menos indirectamente, y en forma artificial, a toda la colectividad nacional. Y en unos casos para remunerar un trabajo, que desearía otra clase de remuneración, sin duda, menos gravosa, para el conjunto de la sociedad española; y en otros casos, y esto es más grave, para remunerar a un capital ocioso, insolidario, y residual de un pasado lejano, que se aviene mal con los tiempos de hogaño. Ésta es una disarmonía que puede, y debe encontrar entre otras, una solución que haga armónica la explotación agraria de la región, que requiere otra clase de armonías muy distintas a las armonías de que también están necesitadas otras. 